\title{
Study on the Online Testing Technology of Oilfield Distribution Transformer Loss
}

Sun Dong ${ }^{1}$

Technical Inspection Center of Shengli Petroleum

Administration Bureau

Dongying, Shandong Province, China

E-mail: sdsdsd_79@sina.com

Bai Jinqiang ${ }^{2}$

China University of Petroleum(East China)

Qingdao, Shandong Province, China

E-mail: baijinqiangbryan@gmail.com

\begin{abstract}
At present, there are many different kinds of transformers in the oilfield, How to identify the high loss transformer, realize the transformer economic operation, which has important significance in saving electricity and reducing oilfield enterprises operating cost. This paper expounds the on-line measurement principles of the transformer loss, and according to the characteristics of the oilfield distribution transformer, designs the transformer loss online testing system, which can synchronously acquire the voltage, current signal of the transformer original and secondary side, and achieve the on-line transformer loss measuring. Field tests show that the test system proposed in this paper, can on-line analysis transformer loss, and analysis the change of the transformer loss in the situation of pumping unit generating electricity, harmonic interference and fluctuation of load. This research will provide technical support for oilfield enterprises to identify the high loss transformer and reasonably select energy-saving transformer, thus achieve the goal of saving energy and reducing consumption.
\end{abstract}

Keywords-transformer loss; online testing;

Rogowski coil; pumping unit; energy-saving

\section{INTRODUCTION}

Oilfield distribution network has the characteristics of large scale, much equipment, complicated structure and low load rate, in the operation and management, due to laying particular stress on reliability but despising economy, electricity losses are very serious [1]. With the particularity of oilfield production, distribution transformer has a serious phenomenon that we said "big Mara trolleys", thus the distribution transformer losses account for a large percentage [2-3]. According to statistics, distribution transformer loss is about 30 50 TW $\cdot \mathrm{h}$ per year, accounts for about $3 \% \sim 4 \%$ of the total generating capacity [4]. Electric energy waste is huge, and some of the transformer with parameters aging, higher losses, more defects and poor reliability, has a serious threat to the safe operation of power grid. Therefore, it has great significance to reduce the loss of distribution

\author{
$\mathrm{Li} \mathrm{Wei}^{3}$
}

Technical Inspection Center of Shengli Petroleum

Administration Bureau

Dongying, Shandong Province, China

E-mail:

Fan $\mathrm{Lu}^{4}$

Technical Inspection Center of Shengli Petroleum

Administration Bureau

Dongying, Shandong Province, China

E-mail:

transformer and improve the efficiency of the transformer, both in implementing the strategy of low cost of oilfield [5] and in alleviating the power shortage.

In order to reduce the transformer losses, we must have the corresponding transformer loss testing technique and means. Now, the main transformer loss measurement is through the offline no-load and short-circuit test [6], which can more easily measure the new transformer. However, for the transformer which is in operation, if removed, there will not only waste a lot of manpower and material resources, but also affect the continuity of power supply and the normal production of oilfield, there are a lot of disadvantages. In view of this situation, a new online testing system of transformer loss is proposed in this paper, which can acquire the transformer input electrical parameters, and synchronously acquire the output electrical parameters. Through the comparison and analysis of input and output electrical parameters of transformer, the loss of transformer can be calculated. This system breaks through the theoretical calculation method of transformer loss, can online monitor the transformer loss in the situation of pumping unit generating electricity, load fluctuations and harmonic interference, can predict transformer faults, and has great significance in eliminating high loss transformer.

\section{THE TECHNICAL DIFFICULTIES OF ONLINE} TRANSFORMER LOSS TESTING

\section{A. Oilfield Pumping Unit Load Variety}

The working characteristic of pumping unit is overloaded start and alternating load running [7]. The pumping unit load is pulse load, the curve of pumping unit load torque and power is shown in Fig. 1. In the power generation process of pumping unit, the output power and time varies with the actual working condition [8]. For this type distribution transformer loss measurement, the online testing instrument needs 
wide measurement range and fast response speed, so as to adapt to the characteristics of the pumping unit load.

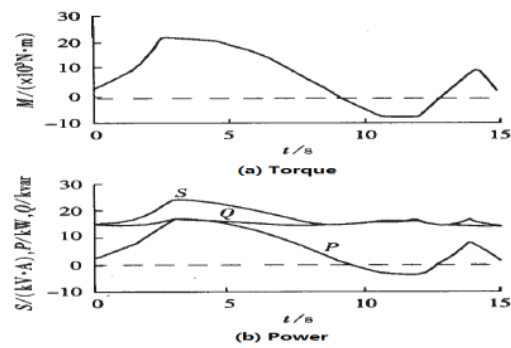

Figure 1. The torque and power curve of pumping unit load

\section{B. Lack of High Voltage Testing Techniques}

On the market, low voltage $(<600 \mathrm{~V})$ testing instruments and techniques have been relatively mature, but the testing instrument for $6 / 10 \mathrm{KV}$ is quite scarce. Distribution transformer input side has high voltage but small current, in order to avoid the traditional voltage sensor magnetic saturation, the transformer range must be wide, as a result the transformer volume will be increased, it is not suitable for transformer online test. The measurement accuracy of current sensor must be ensured, the electrical isolation and dielectric strength will be faced with a major test, and most of the distribution transformers are overhead, which is not suitable for measuring. Therefore, in order to online test transformer loss, mature testing technology and equipments are needed, based on this situation, this paper chooses the appropriate method of online testing, the details see Section 3.

\section{Various Transformer Loads}

Oilfield power load mainly include periodic pumping unit load, continuous water pump and oil pump load and three-phase unbalanced lighting load[9]. These loads are dispersed in oil wells, petrol station and depot. Because these are dispersed in so many spots, too long lines and quite wide area, there will spend a lot of manpower and material resources on testing their distribution transformers. Oilfield distribution transformer load could be one of the above three kinds of load, or several. A transformer can supply power to multiple devices which is in the same type load, or a device needs many transformers for its power supply. Power distribution network is so complicated that it is difficult to guarantee the testing synchronicity.

\section{THE ONLINE TESTING PRINCIPLE OF}

\section{TRANSFORMER LOSS AND SYSTEM DESIGN}

\section{A. The Online Detection Method of TransformerLoss}

Transformer equivalent circuit is often used for related research, now the single phase double winding transformer is took as the research object, its transient equivalent circuit [10-11] is shown in Fig. 2.

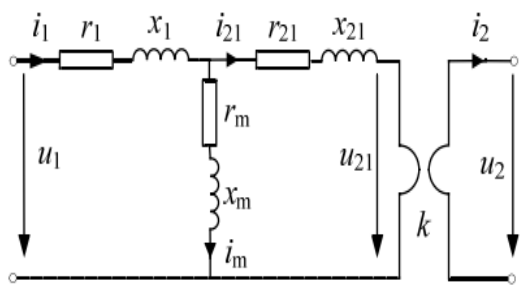

Figure 2. The transformer transient equivalent circuit

As is shown in Fig. 2, $r_{1} 、 x_{1}$ is primary winding resistance, reactance. $r_{21} 、 x_{21}$ is the primary winding equivalent value of secondary winding resistance, reactance. $r_{m} 、 x_{m}$ is the excitation resistance, reactance. $u_{1} 、 i_{1}$ is the instantaneous voltage, current value in the primary side. $u_{2} 、 i_{2}$ is the instantaneous voltage, current value in the secondary side. $u_{21} 、 i_{21}$ is the primary equivalent value of secondary instantaneous voltage, current. $i_{m}$ is the excitation current. $k$ is the ratio. The RMS value of voltage, current and power can be expressed as:

$$
\begin{gathered}
U=\sqrt{\frac{1}{T} \int_{0}^{T} u^{2}(t) d t} \\
I=\sqrt{\frac{1}{T} \int_{0}^{T} i^{2}(t) d t} \\
P=\frac{1}{T} \int_{0}^{T} p(t) d t=\frac{1}{T} \int_{0}^{T} u(t) i(t) d t
\end{gathered}
$$

Depending on the equivalent circuit, we can get:

$$
\begin{gathered}
P_{1}=\frac{1}{T} \int_{0}^{T} u_{1} i_{1} d t \\
P_{2}=\frac{1}{T} \int_{0}^{T} u_{2} i_{2} d t
\end{gathered}
$$

$P_{1}$-input power, $P_{2}$-output power.

The total losses of transformer:

$$
\begin{aligned}
& \Delta P=P_{1}-P_{2}=\frac{1}{T} \int_{0}^{T} u_{1} i_{1} d t-\frac{1}{T} \int_{0}^{T} u_{2} i_{2} d t \\
& =\frac{1}{T} \int_{0}^{T} u_{1}\left(i_{1}-\frac{i_{2}}{k}\right) d t+\frac{1}{T} \int_{0}^{T} i_{2}\left(\frac{u_{1}}{k}-u_{2}\right) d t=P^{\prime}+P^{\prime \prime}
\end{aligned}
$$

Among them:

$$
\begin{aligned}
& P^{\prime}=\frac{1}{T} \int_{\mathrm{O}}^{T} u_{1}\left(i_{1}-\frac{i_{2}}{k}\right) d t \\
& P^{\prime \prime}=\frac{1}{T} \int_{\mathrm{O}}^{T} i_{2}\left(\frac{u_{1}}{k}-u_{2}\right) d t
\end{aligned}
$$

With load, the voltage drop of the transformer primary winding leakage resistance is just a few percent of the rated voltage, and the excitation current is far less than rated current, is about $3 \%$ to $8 \%$ of rated current, large transformer even less than $1 \%$, so deriving from (4), we can get [5]: 


$$
\begin{aligned}
& P^{\prime}=\frac{1}{T} \int_{O}^{T} u_{1}\left(i_{1}-i_{21}\right) d t=\frac{1}{T} \int_{O}^{T} u_{1} i_{m} d t=P_{F e} \\
& P^{\prime \prime}=\frac{1}{T} \int_{0}^{T} \frac{i_{2}}{k}\left(u_{1}-k u_{2}\right) d t=\frac{1}{T} \int_{0}^{T} i_{21}\left(u_{1}-u_{21}\right) d t=P_{C u}
\end{aligned}
$$

For single-phase transformer, the actual operational iron losses $P_{F e}$ and copper loss $P_{C u}$ can be expressed as:

$$
\begin{aligned}
& P_{F e}=\frac{1}{T} \int_{O}^{T} u_{1}\left(i_{1}-\frac{i_{2}}{k}\right) d t \\
& P_{C u}=\frac{1}{T} \int_{O}^{T} i_{2}\left(\frac{u_{1}}{k}-u_{2}\right) d t
\end{aligned}
$$

Distribution transformer mainly include Y-yn0 and D-yn11 connection three-phase oil-immersed type and dry type transformer, the two types of distribution transformer loss on-line detection methods are analyzed as fellows.

Y-yn0 connection distribution transformer wiring diagram is shown in Fig. 3.

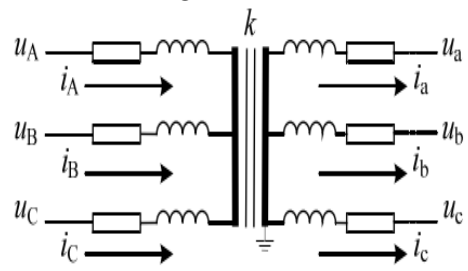

Figure 3. Y-yn0 connection distribution transformer

$$
\text { wiring diagram }
$$

The total losses can be deduced according to (3):

$$
\begin{gathered}
\Delta P=\frac{1}{T} \int_{0}^{T} u_{A}\left(i_{A}-\frac{i_{a}}{k}\right) d t+\frac{1}{T} \int_{0}^{T} i_{a}\left(\frac{u_{A}}{k}-u_{a}\right) d t \\
+\frac{1}{T} \int_{0}^{T} u_{B}\left(i_{B}-\frac{i_{b}}{k}\right) d t+\frac{1}{T} \int_{0}^{T} i_{b}\left(\frac{u_{B}}{k}-u_{b}\right) d t \\
+\frac{1}{T} \int_{0}^{T} u_{C}\left(i_{C}-\frac{i_{c}}{k}\right) d t+\frac{1}{T} \int_{0}^{T} i_{c}\left(\frac{u_{C}}{k}-u_{c}\right) d t=P_{F e}+P_{C u}
\end{gathered}
$$

The transformer copper loss and iron loss can be represented as:

$P_{F e}=\frac{1}{T} \int_{0}^{T}\left[u_{A}\left(i_{A}-\frac{i_{a}}{k}\right)+u_{B}\left(i_{B}-\frac{i_{b}}{k}\right)+u_{C}\left(i_{C}-\frac{i_{c}}{k}\right)\right] d t$

$P_{C u}=\frac{1}{T} \int_{0}^{T}\left[i_{a}\left(\frac{u_{A}}{k}-u_{a}\right)+i_{b}\left(\frac{u_{B}}{k}-u_{b}\right)+i_{c}\left(\frac{u_{C}}{k}-u_{c}\right)\right] d t$

Each phase voltage and current of Y-yn0 connection transformer can be directly measured, and transformer iron loss and copper loss can be calculated by (8). But for D-yn11 connection transformer, as shown in Fig. 4, the original edge phase current cannot be directly measured, the measured line current is needed to be converted into phase current, then can be calculated by (8).

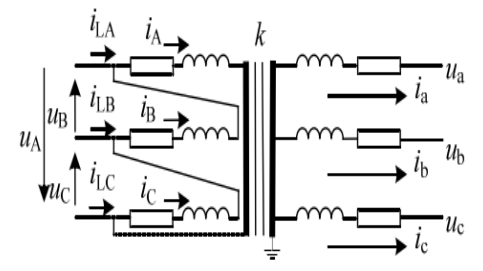

Figure 4. D-yn11 connection distribution transformer wiring diagram

As shown in Fig. 4, $i_{L A} 、 i_{L B} 、 i_{L C}$ is the line current, can be represented as:

$$
\left\{\begin{array}{l}
i_{L A}=i_{A}-i_{B} \\
i_{L B}=i_{B}-i_{C} \\
i_{L C}=i_{C}-i_{A}
\end{array}\right.
$$

Because $i_{L A}+i_{L B}+i_{L C}=0$, from (9), each phase current can be expressed as:

$$
\left\{\begin{array}{l}
i_{A}=\left(i_{L A}-i_{L C}\right) / 3 \\
i_{B}=\left(i_{L B}-i_{L C}\right) / 3 \\
i_{C}=\left(i_{L C}-i_{L A}\right) / 3
\end{array}\right.
$$

Through the above analysis, we can see: for different connection type, according to the real-time measurement of the primary, secondary edge phase voltage and current, the transformer iron loss and copper loss can be calculated through (8), thus the transformer loss online test can be implemented.

\section{B. Transformer Loss Online Test System}

To realize the distribution transformer loss online test, the primary, secondary side voltage and current of transformer must be sampled synchronously, and the correlation algorithm is needed for analysis. The schematic diagram of online test system designed in this paper is shown in Fig. 5.

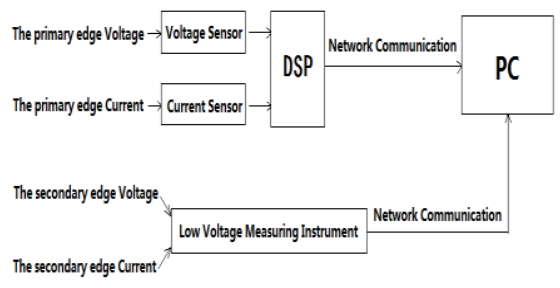

Figure 5. Transformer loss online test system schematic diagram

The oilfield distribution transformer primary side voltage, current signal conversion were realized through the independent developing high voltage electronic voltage sensor and PCB Rogowski coil current sensor, and the voltage, current signal were sampled by the DSP F28335, The sample data was transmitted to the host computer through the network interface, the secondary side voltage, current signal were synchronously sampled by low voltage measuring instrument(HIOKI 3390), the sampled data was also transmitted to host computer through network interface, the host computer completed the data analysis, and finally the analysis results were displayed in a graphical interface, the transformer loss online measuring was realized.

In view of the oilfield distribution transformer load characteristic, based on the research status of the high voltage (6-10KV) measuring instrument, the transformer primary side current signal was acquired through PCB Rogowski coil current sensor, as is 
shown in Fig. 6, which is first proposed in this paper. Host computer control and data processing analysis software was independent developed. The transformer primary side self-developed test system and secondary side low voltage measuring instrument (HIOKI 3390) were controlled by host computer through the network interface, the transformer primary and secondary side electrical parameters synchronous sample was realized, thus the transformer losses were acquired.

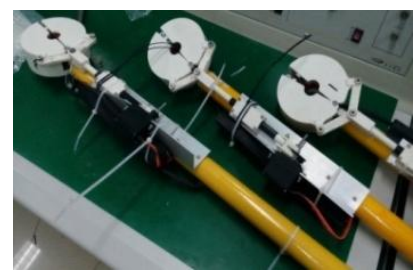

Figure 6. PCB Rogowski coil current sensor photo

\section{FIELD DATA ANALYSIS}

With the transformer loss test system designed in this paper, distribution transformer losses in the situation of load fluctuation, harmonic interference and pumping unit generating electricity were tested and analyzed in ShengLi oilfield.

Case 1: The impact of load fluctuations on the transformer loss

The distribution transformer of pumping unit load, electric submersible pump load were measured, test data are shown in TABLE I. C44-P6 well distribution transformer load is electric submersible pump load, C45-P1 distribution transformer load is well pumping unit load. The active power test waveform of distribution transformer with pumping unit load is shown in Fig. 7, and the electric submersible pump load is shown in Fig. 8.

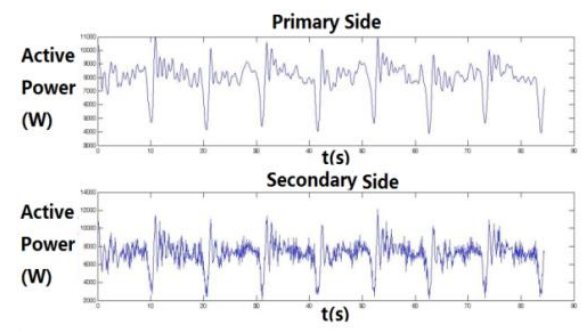

Figure 7. The active power test waveform of distribution transformer with pumping unit load

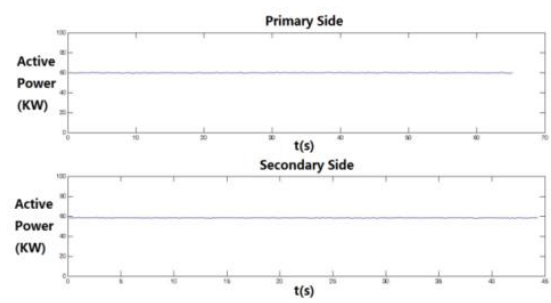

Figure 8 . The active power test waveform of distribution transformer with electric submersible pump load
TABLE I. THE TRANSFORMER TEST DATA UNDER DIFFERENT LOAD

\begin{tabular}{|c|c|c|c|c|c|}
\hline $\begin{array}{c}\text { We11 } \\
\text { No. }\end{array}$ & \multicolumn{2}{|c|}{ Active Power (kw) } & Losses & Efficiency & Notes \\
\cline { 2 - 6 } & Primary & Secondary & (kw) & Ratio(\%) & \\
\hline C44-P6 & 59.79 & 58.42 & 1.37 & 97.71 & $\begin{array}{c}\text { Submersible } \\
\text { pump }\end{array}$ \\
\hline C45-P1 & 8.07 & 7.23 & 0.84 & 89.59 & Pumping unit \\
\hline
\end{tabular}

From Fig. 7 and 8, we can see that pumping unit load is periodical alternating load, fluctuation is bigger than electric submersible pump load. By comparison in TABLE I, we can see that the distribution transformer efficiency of pumping unit is only $89.59 \%$, but the distribution transformer efficiency of electric submersible pump reached $97.71 \%$, the losses are relatively smaller than the pumping unit. From this, we conclude that load fluctuation has direct influence to the loss of transformer, for variable load conditions, such as pumping unit load, the relevant formula in the standard "power transformer economical operation (GB/T 13462-2008)" cannot be applied to estimate the losses of transformer.

Case 2: The impact of pumping unit generating electricity on the transformer loss

A certain "one with two" system distribution transformer was tested, which is a transformer supply for two pumping unit, the test data are shown in TABLE II. The transformer primary side active power and the C93 - P1 well, C45 - P13 well control cabinet input active power test waveform is shown in Fig. 9.

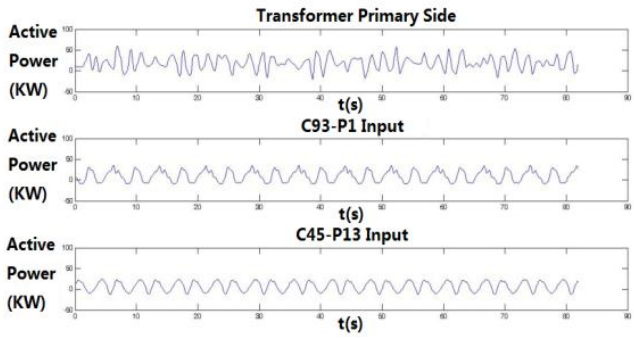

Figure 9. The active power test waveform

TABLE II. A CERTAIN "ONE WITH TWO" SYSTEM DISTRIBUTION TRANSFORMER TEST DATA

\begin{tabular}{|c|c|c|c|c|c|c|}
\hline \multirow[t]{2}{*}{ Well No. } & \multicolumn{2}{|c|}{$\begin{array}{l}\text { Mean Active } \\
\text { Power (kw) }\end{array}$} & \multicolumn{2}{|c|}{$\begin{array}{l}\text { Mean Negative } \\
\text { Power (kw) }\end{array}$} & \multirow{2}{*}{$\begin{array}{l}\text { Losses } \\
(\mathrm{kw})\end{array}$} & \multirow[t]{2}{*}{$\begin{array}{l}\text { Efficiency } \\
\text { Ratio(\%) }\end{array}$} \\
\hline & Primary & Secondary & Primary & Secondary & & \\
\hline C93-P1 & \multirow{2}{*}{19.57} & 7.27 & \multirow{2}{*}{-1.33} & -2.29 & \multirow{2}{*}{2.08} & \multirow{2}{*}{$89.37 \%$} \\
\hline C45-P13 & & 10.22 & & -1.89 & & \\
\hline
\end{tabular}

From Fig. 9, we can see that the two pumping unit have negative power, that is "generating electricity" phenomenon. TABLE II shows that the average negative power of C93-P1 well, C45-P13 well is -2.29 
$\mathrm{kW}$ and $-1.89 \mathrm{~kW}$, but the distribution transformer primary side average negative power is $-1.33 \mathrm{~kW}$. From this, we can see that pumping unit system can release electricity to the grid, the transformer loss increases, transformer efficiency decrease, but there is no relevant standard to measure or evaluate this feedback electricity, and the influence to the transformer loss cannot be calculated.

Case 3: The impact of harmonic interference on the transformer loss

A one DC generatrix "one with five" system distribution transformer was tested, that is the alternating current through the transformer, then through AC/DC transform, was transformed into DC current, and it was transferred to each wells through DC generatrix. At the power distribution cabinet, the DC current was transformed into alternating current through DC/AC transform, then supply for pumping unit motor. The tested transformer supplies for five belt type pumping unit, the test data is shown in TABLE III. The transformer primary side voltage, current and active power test waveform is shown in Fig. 10. The transformer voltage and current harmonic distribution is shown in Fig. 11.

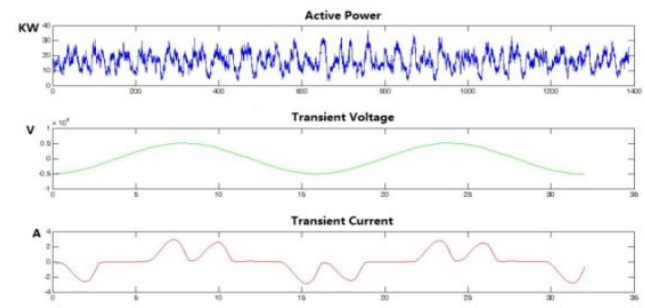

Figure 10. The transformer primary side voltage, current and active power test waveform

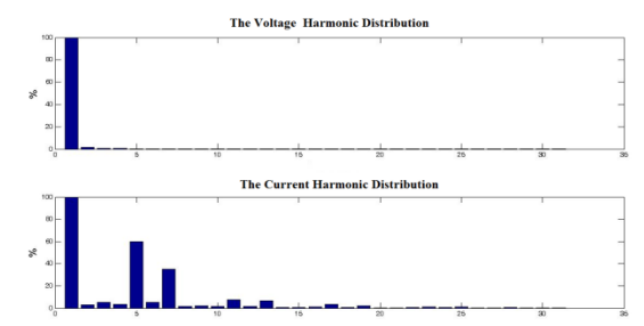

Figure 11. The transformer voltage and current harmonic distribution

TABLE III. A ONE DC GENERATRIX "ONE WITH FIVE" SYSTEM DISTRIBUTION TRANSFORMER TEST DATA

\begin{tabular}{|c|c|c|c|c|}
\hline \multirow{2}{*}{ Well No. } & \multicolumn{2}{|l|}{ Active Power (kw) } & Losses & Efficiency \\
\cline { 2 - 3 } & Primary & Secondary & (kw) & Ratio(\%) \\
\cline { 1 - 1 } C45-P8 & & 2.57 & & \\
\cline { 1 - 1 } C45-P10 & & 3.72 & & \\
\cline { 1 - 1 } C45-P7 & \multirow{2}{*}{16.53} & 2.64 & \multirow{2}{*}{1.47} & \multirow{2}{*}{$91.11 \%$} \\
\cline { 1 - 1 } C45-P4 & & 3.45 & & \\
\cline { 1 - 1 } C71-P14 & & 2.68 & & \\
& & & & \\
& & & & \\
\hline
\end{tabular}

From Fig. 10, we can see that due to rectifier and inverter technology, transformer primary side current has a certain degree of distortion-double peak. From Fig. 11, we can see that 5 and 7 times harmonic in current is more than others. TABLE III shows the transformer efficiency decreases, loss increases relatively. According to the testing data, its current harmonic content has reached the $6 \mathrm{KV}$ power harmonic content that standard "GB/T14549-1993 utility grid harmonic "stipulated. There is also no specific theoretical formula for calculating their impact on the transformer loss.

\section{CONCLUSION}

The field experiments show that the impact of the load fluctuation, pumping unit generating power and harmonic interference on the transformer loss cannot be calculated through clear theoretical formula at present. However, the oilfield distribution transformer can be online tested by the testing system which is designed in this paper, which can effectively analyze the transformer operating loss. It has important engineering significance in identifying the high loss of transformer in different working conditions, and provides technical support for saving energy and reducing consumption in oilfield.

\section{REFERENCES}

[1] Chen Shuhua. Research on 10KV Power Saving Energy and Reducing Consumption. Technology and Business, 2012(11): 166.

[2] Chen Guocheng, Dai Chaoren. The Energy Saving Operation of the Oil Bump Transformer by Means of Adjustable Capacity. Transformer, 1997, 34(8): 35-36.

[3] Li Jiandong, Yuan Fengjun, Deng Ping. The Application of Energy-intensive Transformer Energy-saving Technology in Gudao Oil Production Plant. Electrical Applications, 2011,30 (23): 52-54, 84.

[4] Hao Lingxia. The Loss Analysis of Distribution Transformer and Loss Reduction Measures. Power Supply Technologies and Application, 2012 (12):97-98.

[5] Wu Xihong. Research on the Online Detection Method for the Loss and Capacity of Distribution Transformer. Chongqing University, 2010.

[6] He Wei, Wu Xihong, Wang Ke, etc. Online Detecting Method of Transformer Open-circuit Loss and Short-circuit Loss. Proceedings of the CSU-EPSA, 2010, 22(6): 72-76.

[7] Zheng Yuming. The Development of the Oilfield Special Adjustable Capacity Transformer. OGSE, 2000, 19 (4):53-54.

[8] Zhang Xiaoning, Zhang Baogui, Lu Zeyin, etc. Research and Application of Reactive Power Compensation of Distribution System for Oil-pumping Units. Electric Power Automation Equipment, 2004, 24(4): 57-60.

[9] Shang Debin. Analysis of Oil Pumping Load Peculiarity of ZhongYuan Oilfield and Study of Reactive Power Compensation. China University of Petroleum (East China), 2009.

[10] Cheng Lin. Research on Power Transformer Online Testing. Huazhong University of Science and Technology, 2006.

[11] Arri E, Carta A, Mocci F, Tosi M. Diagnosis of the state of power transformer windings by on-line measurement of stray reactance. IEEE Transactions On Instrumentation and Measurement, 1993, 42(2):372-378. 